\title{
Actualización del límite occidental del pastizal pampeano
}

\author{
Manuel R. Demaría'; Juan P. Martini ${ }^{1} \&$ Diego F. SteinakeR²
}

${ }^{1}$ INTA EEA San Luis. CC 17, (5730)Villa Mercedes, San Luis, Argentina. ${ }^{2}$ Canadian Institute of Ecology and Evolution. University of Regina. Department of Biology. 3737 Wascana Pkwy, Regina, SK S4S 0A2, Canada.

\begin{abstract}
Resumen. Los mapas fitogeográficos y de eco-regiones actuales delimitan la distribución de los pastizales pampeanos argentinos a las provincias de Buenos Aires, Córdoba, Santa Fe, Entre Ríos, La Pampa y San Luis. En este trabajo revisamos su distribución en el extremo occidental por medio de muestreos a campo y análisis digitales de imágenes satelitales, e incorporamos una extensión importante de este ecosistema en las provincias de Mendoza y La Pampa. Para el mapeo satelital usamos una serie temporal de 10 años de imágenes MODIS/Terra. Realizamos una clasificación no supervisada (ISODATA), complementada con una interpretación visual sobre imágenes Landsat 8 de 2014, en dos categorías: pastizal y bosque (arbustal). La precisión total de la clasificación fue $89.1 \%$, verificada a través de una matriz de error con imágenes de alta resolución obtenidas a partir de Google Earth. El análisis digital nos permitió identificar un área de 3050 $\mathrm{km}^{2}$ de pastizal pampeano al oeste del río Salado, en el sureste de la provincia de Mendoza y el centro-norte de La Pampa, entre $35.362^{\circ}$ y $36.257^{\circ} \mathrm{S}$, y $66.613^{\circ}$ y $67.264^{\circ} \mathrm{O}$. Los relevamientos de la vegetación en sitios representativos muestran que áreas antes categorizadas como "monte" reúnen todas las características de un típico pastizal pampeano occidental semiárido, dominando por matas perennes $\mathrm{C}_{4}$ de Elionurus muticus (paja amarga, cobertura 28\%). Otras especies importantes, con coberturas que varían entre 1 y $5 \%$, son Hyalis argentea, Sporoboluscryptandrus, Aristidamendocina, Bothriochloaspringfieldiiy Eragrostislugens. Laaltatasade reemplazo que experimenta la región convierte a estos pastizales en un área de importancia ecológica para la conservación de este ecosistema frágil.
\end{abstract}

[Palabras clave: eco-regiones, análisis digital de imágenes, mapeo, Mendoza, cobertura vegetal, Argentina]

Aвstract. Revising the western boundary of Pampa grasslands. The current mapping on land-cover distribution restricts the Argentinean Pampa grasslands to the Buenos Aires, Córdoba, Santa Fe, Entre Ríos, La Pampa and San Luis provinces. In this study, we reviewed the western distribution of these grasslands by using remote sensing analyses and "in situ" evaluations. We used a 10-years series of MODIS/Terra satellite images as a basis to locate and map the area of study. We also employed a non-supervised classification (ISODATA), complemented with a visual interpretation on Landsat 8 satellite images, to classify pixels into two categories: grassland and shrubland. The accuracy of this classification was $89.1 \%$, verified through an error matrix by using high resolution images from Google Earth. We identified a new area of $3050 \mathrm{~km}^{2}$ of Pampa grasslands that was not considered in previous land-cover vegetation maps. This area, previously categorized as shrublands, is located west of the Salado river, at the south-east of Mendoza and north-center of La Pampa provinces, between $35.362^{\circ}$ and $36.257^{\circ} \mathrm{S}$, and $66.613^{\circ}$ and $67.264^{\circ} \mathrm{W}$. Vegetation surveys in specific sites showed that they are typical semiarid Pampa grasslands, dominated by $\mathrm{C}_{4}$ perennial tussocks of Elionurus muticus ( $28 \%$ of area cover). Other important species, with area covers between 1 and $5 \%$, were Hyalis argentea, Sporobolus cryptandrus, Aristida mendocina, Bothriochloa springfieldii and Eragrostis lugens. The inherent low replacement rate that occurs in this semiarid region of Argentina enhances the importance of these grasslands as reservoirs of this fragile ecosystem.

[Keywords: ecoregions, remote sensing analysis, mapping, Mendoza, land cover, Argentina]

\section{INTRODUCCIÓN}

Los pastizales pampeanos se extienden sobre una planicie extensa en el centro-este de Argentina, Uruguay y el sur del estado brasileño de Río Grande del Sur (Soriano 1991) (Figura 1). En la República Argentina, los mapas fitogeográficos y de eco-regiones delimitan la distribución de los pastizales pampeanos a las provincias de Buenos Aires, Córdoba, Santa Fe, Entre Ríos, La Pampa y

\section{Editora asociada: Marina Omacini}

demaria.manuel@inta.gob.ar
San Luis (Soriano 1991; León \& Anderson 1983). Sin embargo, existen evidencias para estudiar la continuación de los pastizales pampeanos hacia el oeste en la provincia de Mendoza, sobre áreas consideradas como perteneciente a la Provincia fitogeográfica del Monte (Cabrera 1953) y caracterizadas como arbustales xerófilos.

En el pasado, la amplia extensión del territorio y las limitaciones de las técnicas tradicionales 
de mapeo dificultaron la delimitación precisa de la región pampeana. Esto generó diferencias entre autores (Figura 1). Los cambios en la cobertura vegetal asociados al avance de la agricultura también dificultan la delimitación y el mapeo de los ecosistemas naturales. Sin embargo, hacia el oeste semiárido de la región pampeana, en donde las condiciones edáficas y climáticas limitan cambios profundos en el uso de la tierra, es aún posible discriminar regiones fitogeográficas por medio de metodologías apropiadas. En este sentido, hoy la teledetección es un recurso clave para la cartografía de los ecosistemas debido a la resolución espacial elevada de algunas imágenes satelitales, que permiten delimitar con gran precisión los tipos de cobertura del terreno (Hansen et al. 2000; Treitz \& Howarth 2000; Lefsky et al. 2002).

El mapa que define la eco-región de pastizales pampeanos sufrió modificaciones con el avance de las investigaciones. Por ejemplo, hoy resulta indiscutible que un cinturón continuo y estrecho de pastizales pampeanos, en principio considerados como pertenecientes a la provincia fitogeográfica del Espinal (Frenguelli 1941; Parodi 1945; Cabrera 1953), penetra en la región boscosa xerófila del oeste en el punto de encuentro entre las provincias de San Luis, La Pampa y Córdoba (León \& Anderson 1983). Luego, Soriano (1991), en su caracterización de los pastizales del Río de la Plata, toma finalmente como límite occidental del pastizal pampeano a los pastizales de la provincia de San Luis y la Pampa (Figura 1). En este trabajo combinamos tecnologías satelitales y muestreo a campo para rediseñar el límite occidental del pastizal pampeano y proponer la incorporación de pastizales naturales localizados en el sureste de Mendoza dentro de este ecosistema.

\section{MATERIAles y MÉTODOS}

\section{Área de estudio}

El estudio se llevó a cabo en una región ubicada en el sureste de la provincia de Mendoza, el suroeste de San Luis y el centro-norte de La Pampa, al oeste de la región delimitada por Soriano (1991) como Pampa Interior Occidental de los pastizales pampeanos (Figura 1). En términos topográficos, es una planicie ligeramente ondulada, con cordones de médanos fijos colonizados por vegetación y la presencia de algunos médanos vivos, de origen antrópico reciente. Los suelos son entisoles de textura arenosa, poco desarrollados, bajo contenido de materia orgánica $(0.7-0.9 \%)$, baja capacidad de retención de agua y muy susceptibles a la erosión eólica (Peña Zubiate et al. 1998).

La vegetación es típica de un pastizal templado semiárido con pastos en mata y presencia aislada de leñosas como caldenes (Prosopiscaldenia),alpatacos(Prosopisalpataco) ybosquecillosdechañar(Geoffroeadecorticans). Las gramíneas dominantes son perennes y de

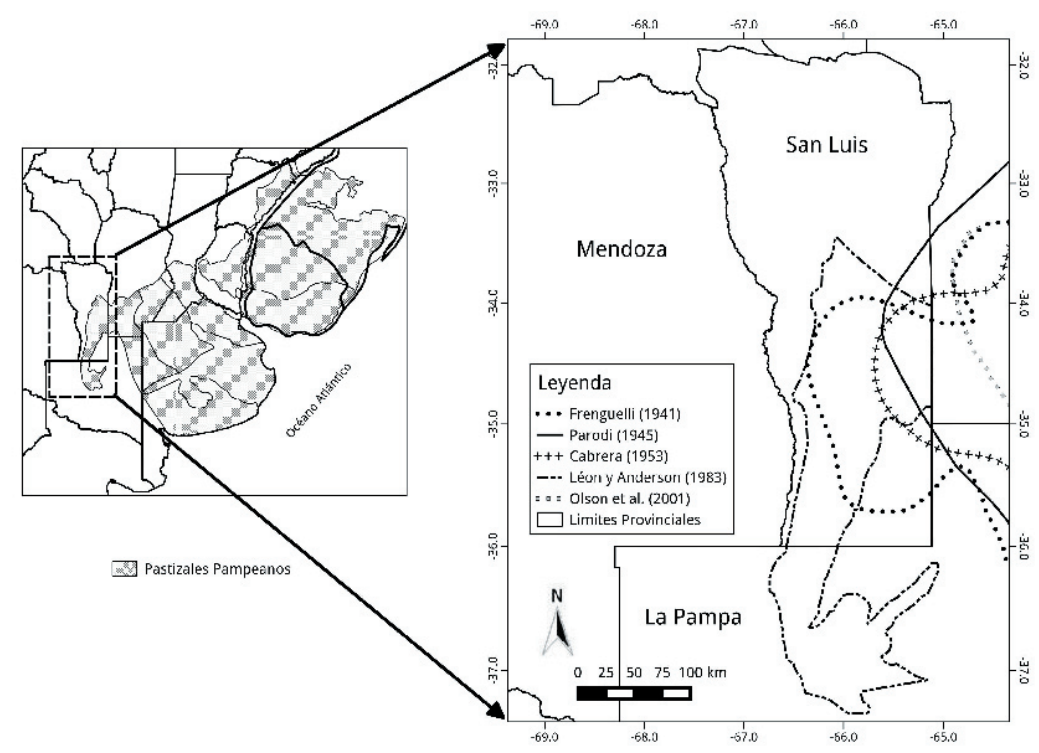

Figura 1. Distribución de los pastizales pampeanos (Soriano 1991; mapa de la izquierda) y límite occidental según distintos autores (derecha).

Figure 1. Pampa's grassland map (Soriano 1991; left panel) and western borderlines according to different studies (right panel). 
vía metabólica $C_{4}$ y los principales géneros son Sorghastrum, Elionurus, Chloris, Eustachis, Sporobolus, Bothriochloa, Eragrostis, Panicum, Cenchrus, Aristida y Schizachyrium. También se encuentran gramíneas perennes $\mathrm{C}_{3}$ y los géneros más comunes son Poa, Stipa, Jarava y Nassella (Anderson et al. 1970, Aguilera et al. 1998).

La precipitación media anual es de $450 \mathrm{~mm}$, con un gradiente decreciente de este a oeste, concentradas en un $80 \%$ entre octubre y abril. Existe una gran amplitud térmica diaria y estacional, con máximas absolutas de $43{ }^{\circ} \mathrm{C}$ en verano y mínimas de $-15^{\circ} \mathrm{C}$ en invierno (Capitanelli \& Zamorano 1972).

\section{Mapeo del pastizal}

Para el mapeo del límite occidental del pastizal pampeano se utilizó una serie temporal NDVI de 10 años (agosto de 2000 a julio de 2010) obtenidos a partir del sensor MODIS del satélite Terra (producto MOD13Q1). Este producto presenta una resolución espacial de $250 \mathrm{~m}$ y una resolución temporal de 16 días. Sobre esta serie se realizó una clasificación no supervisada utilizando el algoritmo ISODATA con 30 clases. El número máximo de interacciones empleado fue de $10 \mathrm{y}$ el umbral de convergencia usado fue 0.95 . Las 30 clases obtenidas fueron recategorizadas en dos clases diferentes a partir de una interpretación visual utilizando como capas de referencia imágenes Landsat 8 de 2013 (Clement \& Pontius 2008): 1) Pastizal Pampeano, 2) Áreas Boscosas.

La precisión de la imagen clasificada fue verificada a través de una matriz de error (Jensen 1996). Se seleccionaron 50 píxeles de verificación en el área asociada a los pastizales pampeanos de Mendoza mediante un muestreo estratificado al azar (Hay 1979; Congalton 1991; Stein et al. 1999). Estos píxeles de verificación fueron categorizados por medio de imágenes de alta resolución obtenidas de Google Earth. Por otro lado, en junio de 2010 se realizó un recorrido de $150 \mathrm{~km}$ por el área de estudio para una verificación "in situ" del tipo de paisaje y vegetación. Durante este recorrido se realizaron paradas regulares cada $5 \mathrm{~km}$ para registrar visualmente el tipo de ambiente observado (pastizal - monte).

\section{Caracterización de la vegetación}

Dentro de la nueva área identificada como pastizales pampeanos en el sureste de la provincia de Mendoza, en julio de 2011 se llevó a cabo la caracterización de la vegetación "in situ" a través de censos de vegetación. Se seleccionaron sólo dos sitios representativos de ese pastizal debido a la inaccesibilidad del área estudiada: sitio $1\left(35.42959^{\circ} \mathrm{S} 66.81131^{\circ}\right.$ O) y sitio $2\left(35.44846^{\circ} \mathrm{S} 66.82449^{\circ} \mathrm{O}\right)$. Estos sitios cumplieron los requisitos de 1) presentar topografía plana (inclinación $<1 \%$ ), 2) ser una zona intermedia entre una loma y un bajo, 3 ) no tener aguadas para el ganado a menos de $700 \mathrm{~m}$, y 4) no presentar otro tipo de cobertura vegetal a menos de $5 \mathrm{~km}$. En cada sitio se midió densidad y cobertura de todas las especies vegetales presentes siguiendo la metodología propuesta por Daubenmire (1959). Se evaluaron un total de 30 parcelas de $0.1 \mathrm{~m}^{2}$ distribuidas al azar.

\section{RESUltAdOS Y Discusión}

A través del análisis digital de la serie temporal identificamos una porción de $3050 \mathrm{~km}^{2}$ de pastizal pampeano al oeste del río Salado en el sureste de la provincia de Mendoza y en el centro-norte de La Pampa, entre los paralelos $35.362^{\circ}$ y $36.257^{\circ} \mathrm{S}$, y los meridianos $66.613^{\circ}$ y $67.264^{\circ} \mathrm{O}$ (Figura 2).

La precisión total de la clasificación fue 89.13\%. Para las clases Pastizal pampeano y

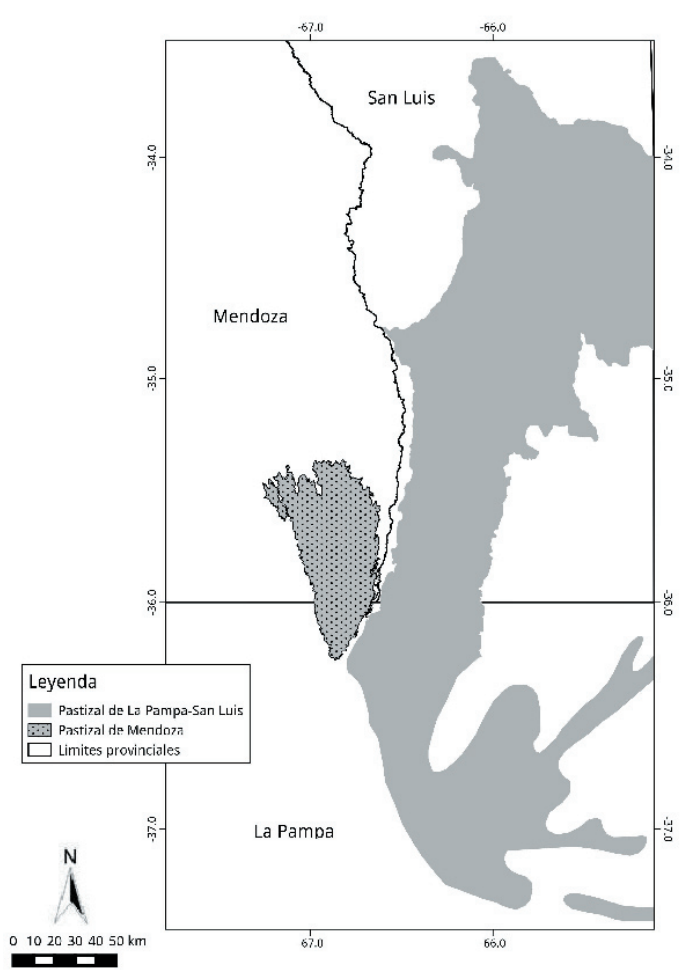

Figura 2. Nuevo límite occidental del pastizal pampeano obtenido a partir del análisis digital de imágenes satelitales.

Figure 2. New western boundary of Pampa's grasslands according this study. 
Áreas Boscosas, la precisión del productor (complementario del error por omisión) fue $87.5 \%$ y $92.8 \%$, respectivamente. Para las dos clases, la precisión del usuario (complementario del error por comisión) fue $96.5 \%$ y $76.5 \%$, respectivamente.

El área de pastizal identificada se caracteriza por la ausencia total de árboles y arbustos típicos de la provincia fitogeográfica del Monte, y por la presencia y distribución aislada de las especies leñosas $P$. alpataco y $G$. decorticans, típicas del pastizal pampeano de San Luis y La Pampa (Figura 3). El pastizal se trata de un "Pajonal de Elionurus y especies estivales e invernales" (Estado " $\mathrm{N}$ ", Aguilera et al. 1998). Las especies dominantes son Elionurus muticus (cobertura 28\%, densidad $13.5 \mathrm{ind} / \mathrm{m}^{2}$ ), Hyalis argentea (cobertura $5 \%$, densidad1.5ind $\left./ \mathrm{m}^{2}\right)$,ySporoboluscryptandrus (cobertura 2\%, densidad 11.4 ind $/ \mathrm{m}^{2}$ ). Otras especies importantes del pastizal son Aristida mendocina,Bothriochloaspringfieldii.Eragrostis lugens, Panicum urvilleanum y Poa lanuginosa (Tabla 1). Todas las especies identificadas forman parte de las comunidades típicas del pastizal pampeano de San Luis, con coberturas y densidades típicas de los pastizales pampeanos de la región semiárida (Aguilera et al. 1998) (Tabla 1).

El análisis digital de imágenes permitió mapear con precisión el verdadero límite occidental del pastizal pampeano e identificar una extensión de este ecosistema al oeste del río Salado, en el sureste de la provincia de Mendoza y centro-norte de La Pampa. Teniendo en cuenta las restricciones edáficas y climáticas de la zona para la agricultura (precipitación $<400 \mathrm{~mm} /$ año) y las altas tasas de reemplazo observadas en áreas con mayor aptitud agrícola sobre la provincia de San Luis (Demaría et al. 2008), es probable que estos pastizales de Mendoza y oeste de La Pampa constituyan en el futuro un área relevante para la conservación de este ecosistema.

Tabla 1. Cobertura absoluta (\%) y densidad (ind $/ \mathrm{m}^{2}$ ) de las especies más comunes de los pastizales pampeanos de Mendoza ( $\left.35.4^{\circ} \mathrm{S}, 66.8^{\circ} \mathrm{S}\right)$. También se reportan los porcentajes de suelo desnudo y broza vegetal. Nomenclatura: Zuloaga \& Morrone $(1996,1999)$ y Zuloaga et al. (1994), actualizadas en www.darwin.edu.ar/ Proyectos/FloraArgentina/Especies.asp y en www.flo raargentina.edu.ar.

Table 1. Absolute cover (\%) and density (ind $/ \mathrm{m}^{2}$ ) of most abundant species, and percentage of bare soil (suelo desnudo) and mulch (broza), at the Mendoza's Pampa grasslands $\left(35.4^{\circ} \mathrm{S}, 66.8^{\circ} \mathrm{W}\right)$. Nomenclature: Zuloaga \& Morrone $(1996,1999)$ and Zuloaga et al. (1994), updated in www.darwin.edu.ar/Proyectos/FloraArgentina/ Especies.asp and in www.floraargentina.edu.ar

\begin{tabular}{lcc}
\hline \multicolumn{1}{c}{ Especie } & $\begin{array}{c}\text { Cobertura } \\
(\%)\end{array}$ & $\begin{array}{c}\text { Densidad } \\
\left(\mathrm{ind} / \mathrm{m}^{2}\right)\end{array}$ \\
\hline Elionurus muticus & 27.92 & 13.46 \\
Hyalis argentea & 5 & 10.79 \\
Sporobolus cryptandrus & 2.03 & 11.04 \\
Prosopis alpataco & 1.66 & 0.75 \\
Aristida mendocina & 1.35 & 2.25 \\
Bothriochloaspringfieldii & 1.21 & 0.75 \\
Poa lanuginosa & 0.89 & 8.17 \\
Eragrostis lugens & 0.15 & 1.5 \\
Panicum urvilleanum & 0.12 & 1.5 \\
Jaraba ichu & 0.08 & 0.01 \\
Suelo desnudo & 15.80 & \\
Broza & 45.79 & \\
\hline
\end{tabular}

Figura 3. Pastizal pampeano occidental en el sureste de la provincia de Mendoza (35.42959 ${ }^{\circ} \mathrm{S}$, $66.81131^{\circ} \mathrm{O}$ ), dominado por Elionurus muticus, Hyalisargentea,Sporobolus cryptandrus, Aristida mendocina, Bothriochloa springfieldii. Eragrostis lugens,Panicumurvilleanum y Poa lanuginosa (Tabla 1).

Figure 3. Pampa's grassland in Mendoza province, Argentina $\left(35.42959^{\circ} \mathrm{S}, 66.81131^{\circ}\right.$ W). More common species are Elionurus muticus, Hyalis argentea, Sporobolus cryptandrus, Aristida mendocina, Bothriochloa springfieldii. Eragrostislugens, Panicum urvilleanum and Poa lanuginosa (Table 1). 
Agradecimientos. Agradecemos al Ing. Agr. Carlos Magallanes y al Ing. Rec. Nat. Daniel Arroyo por la información brindada y el apoyo en el muestreo de campo. Agradecemos a la Dra. Victoria Marchesini por la lectura crítica del manuscrito. Este estudio fue financiado por el Instituto Nacional de Tecnología Agropecuaria (INTA) a través del Proyecto Nacional "Desarrollo, Integración y Transferencia de Tecnologías para Manejo Sustentable de Servicios de la Vegetación Natural para Fines Ganaderos".

\section{REFERENCIAS}

Aguilera, MO; DF SteinaKer; MR Demaría \& AO Ávila. 1998. Estados y transiciones de los pastizales de Sorghastrum pellitum del área medanosa central de San Luis, Argentina. Ecotropicos, 11:107-120.

Anderson, DL; JA Del Águila \& AE Bernardón. 1970. Las formaciones vegetales de la provincia de San Luis. Rev. Inv. Agrop. INTA, 7:83-153.

Cabrera, A. 1953. Esquema fitogeográfico de la Rep. Argentina. Rev. Museo La Plata, 8:87-168.

Capitanelli, R \& M Zamorano. 1972. Geografía regional de la Provincia de San Luis. Bol. Est. Geog. U. Cuyo, 20:74-77.

Clement, AA \& RG Pontius JR. 2008. Identifying systematic land-cover transitions using remote sensing and GIS: the fate of forests inside and outside protected areas of Southwestern Ghana. Env. Plan. B Plan. Design, 35:280-295.

Congalton, RG. 1991. A review of assessing the accuracy of classifications of remotely sensed data. Rem. Sens. Envir., 37:35-46.

Daubenmire, RF. 1959. A canopy coverage method. North. Science, 33:43-64.

Demaría, MR; I AguAdo SuÁREZ \& DF STEINAKER. 2008. Reemplazo y fragmentación de pastizales pampeanos semiáridos en San Luis, Argentina. Ecol. Austral, 18:55-70.

Frenguelli, J. 1941. Rasgos principales de la fitogeografía Argentina. Rev. Museo La Plata, 3:65-181.

HANSEN, M; R DeFries; JRG Townshend \& R SOHLBERG. 2000. Global land cover classification at $1 \mathrm{~km}$ resolution using a decision tree classifier. Int. J. Rem. Sensing, 21:1331-1365.

Hay, AM. 1979. Sampling designs to test land-use map accuracy. Phot. Eng. Rem. Sensing, 45:529-533.

JensEn, JR. 1996. Introductory Digital Image Processing: A Remote Sensing Perspective. Prentice Hall, New Jersey.

LeFsKY, MA; WB COHEN; GG PARKER \& DJ HARding. 2002. Lidar remote sensing for ecosystem studies. BioScience, 52: $19-30$

LEÓN, RJC \& DL ANDERSON. 1983. El límite occidental del pastizal pampeano. Tuexenia, 3:67-83.

Olson, DM; E Dinerstein; ED Wikramanayake; ND Burgess, GVN Powell; et al. 2001. Terrestrial ecoregions of the world: a new map of life on Earth. Bioscience 51:933-938.

PARODI, L. 1945. Las regiones fitogeográficas argentinas y su relación con la industria forestal. Pp. 123-132 en: Verdoorn, F (ed.). Plants and Planta Science in Latin America. Waltham, Mass.

Peña Zubiate, CA; DL Anderson; MA Demmi; JL Saenz \& AD’Hiriart. 1998. Carta de suelos y vegetación de la provincia de San Luis. Payne Publishing. San Luis, Argentina.

Soriano, A. 1991. Rio de la Plata Grasslands. Pp. 367-407 en: Coupland, RT (ed.). Ecosystems of the World. Natural Grasslands: Introduction and Western Hemisphere. Elsevier, New York.

Stein, A; FD Meer; Van Der \& B Gorte. 1999. Spatial Statistics for Remote Sensing. Kluwer Academic Publishers, Dordrecht.

TReitz, P \& P HowArth. 2000. High spatial resolution remote sensing data for forest ecosystem classification - an examination of spatial scale. Rem. Sen. Env., 72:268-289. 